\title{
Rethink about the role of rheumatoid factor and anti-citrullinated protein antibody in rheumatoid arthritis
}

\author{
Wang Yu Sung, Wen Chan Tsai* \\ Division of Rheumatology, Department of Internal Medicine, Kaohsiung Medical University Hospital, Taiwan, China
}

\begin{abstract}
Received December 14, 2020 accepted January 4, 2021

Rheumatoid arthritis (RA) is a chronic inflammatory autoimmune disease characterized by joint inflammation and extra-articular manifestations. Many questions in the pathogenesis, clinical manifestation, and disease spectrum are answered after the discovery of the first autoantibody namely rheumatoid factor (RF). The finding of the second autoantibody named anti-citrullinated protein antibody (ACPA), which unearths the importance of protein citrullination process. It further provides the insight how immune cells and complement interact to perpetuate the inflammatory response. These two autoantibodies pave the way for our better understanding of RA. This review article focuses on the history, pathophysiology, and clinical association of these two autoantibodies in RA.
\end{abstract}

Keywords

rheumatoid arthritis $\bullet$ rheumatoid factor $•$ anti-citrullinated protein antibody

\section{Introduction}

Rheumatoid arthritis (RA) is a chronic inflammatory autoimmune disease characterized by progressive destructive joint damage and many extra-articular manifestations. ${ }^{11-3]}$ Joint involvements are usually symmetric with early morning stiffness. Any joint can be involved, although lumbar spine involvements are rarely reported. ${ }^{[4,5]}$ Pulmonary, ocular, and cardiovascular symptoms are common extra-articular manifestations. ${ }^{[6-10]}$ It is a fact that the natural history of RA is quite variable and its clinical course is fluctuating. If left untreated, most patients have poor prognostic joint outcome and might lead to miserable life quality. In addition to clinical finding, laboratory tools are very useful for the diagnosis of RA. As listed in the ACR/EULAR classification criteria, two autoantibodies namely rheumatoid factor (RF) and anticitrullinated protein antibody (ACPA) can be found in more than $60 \%$ of RA patients. ${ }^{[11-14]}$ These two autoantibodies are not only hallmarks of the disease but also suggested to play important role in the pathogenesis of RA.

Pathogenesis of RA is complex and heterologous. ${ }^{[15-17]}$ During the past decade, attention has been given to genetic and several environmental factors such as cigarette smoking and mucosa diseases. The pathogenesis of RA cannot be fully explained by any single factor. It was suggested that the interaction of these factors occurred long before the clinical onset of RA. A pre-clinical case maybe symptomless or with very mild arthralgia, but importantly, autoantibodies are present in their serum up to 13 years prior to the clinical disease. ${ }^{[18,19]}$ It indicated that in this pre-RA stage, reactivity to some self-antigens might trigger limited inflammatory responses followed by tissue injury. The vicious cycles continue to evolve between inflammation and tissue injury together with the interplay among adaptive and innate cells. After long term relentless inflammation, joint symptoms become more persistent and tissue damage more widespread. Some threshold is crossed and clinically apparent RA develops. ${ }^{[20]}$ It is likely that different pathways in the initiation of RA may be used to explain the pathogenesis of the disease in different patient groups, for example: sero-positive vs. sero-negative RA.

This review article focuses on the discussion of two important autoantibodies in RA: RF and ACPA. We will illustrate the association of these autoantibodies with RA in three important aspects: historical observation, the role in the pathogenesis, and finally, the clinical association.

\section{Rheumatoid Factor}

\section{Historical Observation}

As early as 1922, it was found that the serum from patients 
with liver cirrhosis and chronic bronchitis could promote the agglutination of rabbit antibody-sensitized sheep red blood cells. Two decades later, Waaler noted the same observation using serum from patients with $R A .{ }^{[21]}$ Similar observations were reported and intensive attention was devoted to find the factors causing this phenomenon, although the sero-prevalence rate was different. Due to their high association with RA, the serum factors were christened RF by Pike et al. ${ }^{[22,23]}$ This factor was considered important not only in differential diagnosis but also in pathogenesis because it might take part in the pathogenesis of RA. Study group from The Rockefeller University in New York found that immune complex (IC) formed by rabbit antibody to human antigen could remove the RF from RA serum. After further observations, they concluded that the gamma globulin components of IC were the target of RF. ${ }^{24,25]}$ Furthermore, subsequent studies revealed that RF was not specific for RA as several infections and disease conditions also elicit RF development. Interestingly, prevalence studies of RF positivity in those infectious conditions highlighted the importance that the requirement of chronic, constant exposure to microbial antigens was needed for the development of RFs. Animal studies also illustrated that the prolong and intensive immunization is the key step in the induction of RF production. A novel hypothesis was proposed that during the long course of antigen challenge, new antigenic determinants on globulin could be elicited. ${ }^{[26,27]}$

RF now is known to belong to the family of immunoglobulins (Igs) that has different isotypes and affinities directed to the Fc portion of IgG. RF is not specific to RA and has been identified in rheumatic, non-rheumatic conditions and even healthy adults. ${ }^{[28]}$ Genetic and environmental factors contribute to the different worldwide distribution of RF. North American Indians were found to carry highest prevalence of RF in the world. It was reported about $30 \%$ of the population are sero-positive. [29]

\section{The Role in Pathophysiology}

It was long believed that RF might paly important role in the pathogenesis of RA. It is learned from basic immunology that IC can activate complement and trigger the subsequent inflammation, cytotoxicity, and tissue damage. Early efforts were focused to find the evidence of complement activation and resultant complement end products in the synovial tissue. It was reported that RA patients had lower seral complement level together with lower $\mathrm{C} 1 \mathrm{q}$ and $\mathrm{C} 3$ in the synovial fluid. ${ }^{[30,31]}$ Further observation confirmed the presence of end products of complement cascade, C5a, C5a des Arg, and C5b-9 membrane attack complex (MAC) in the joint cavity. ${ }^{[32,33]}$ It was proposed that multiple hits exaggerated the immune response to cross the threshold in developing RA after the long term presence of microbial antigens. The first hit was the induction of RF to IC and the second hit was the activation of complements.

However, RF was found to increase the clearance of IC and the evidence showed that RF-producing B cells may behave as antigen-presenting cells (APCs) and aid the immune response against the infectious antigens. ${ }^{[34,35]}$ Other groups believed the net impact of RF production is protective rather destructive. In addition, as mentioned before, RF was widely present in normal healthy adult. No reason to believe that all these normal adults had extensive inflammatory responses uncovered.

Interestingly, RFs found in normal healthy adults are different from those found in RA patients. Both titers and affinity are low and they are likely produced by CD5+ B cells. Compared with those present in RA serum, they show low level of somatic hyper-mutation and maturation affinity, and are usually polyreactive IgM. ${ }^{[36]}$ These RFs are reminiscent that low affinity IgM RFs are induced by polyclonal B cell activators such as bacterial lipopolysaccharides and Epstein- Barr virus. ${ }^{[37,38]}$ RFs in healthy subjects could be the bystander in the cross-road between inflammation and resolution after an acute infection.

\section{Clinical Association}

Although every RF isotype was observed, IgM RFs are the major RF species in RA and are detected in $60-80 \%$ of RA patients. ${ }^{[39]}$ The ACR/EULAR 2010 criteria for the RA diagnosis adopt both RF and ACPA as part of its content. However, RFs were also found in other autoimmune diseases, such as, systemic lupus erythematosus, primary Sjogren's syndrome, and in non-rheumatic conditions such as chronic liver diseases, leprosy and pulmonary tuberculosis as well as in normal healthy subjects as mentioned above. How to make a clinical judgment in a RF positive subject is an important issue. In contrast to RFs found in healthy subjects, RFs in RA patients usually exhibit affinity maturation with high affinity and are at high titers. These RFs are mostly mono-reactive and produced in a T cell-dependent manner by CD5- B2 cells. However, high titer RF, especially for those higher than $100 \mathrm{IU} / \mathrm{mL}$ in healthy adults, increases the risk of developing $R A .{ }^{[40]}$ The importance of isotype distribution for helping the differential diagnosis was illustrated in several reports. The simultaneously presence of three isotypes $(\lg G, \lg A, \lg M)$ are detected in more than $50 \%$ of RA patients but found fewer than $5 \%$ in other rheumatic diseases. Double positive for $\lg G$ and $\lg A$ in the absence of $\lg M$ is more prevalent in other rheumatic diseases than RA. ${ }^{[41,42]}$

Chronic hepatitis and Sjogren's syndrome are important confounding factors in the diagnosis of RA due to high 
prevalence of RF and RA-like inflammatory joint pain in both diseases. It was reported that the prevalence of RF in chronic hepatitis $B$ and $C$ were $20-75 \%$ and $40-76 \%$ respectively. ${ }^{[43,44]}$ Asian countries have higher prevalence of chronic hepatitis than that of RA. By a simple calculation it is found that the most common disease carrying RF in Asian countries is chronic hepatitis rather than RA. Patients with Sjogren's syndrome also had high prevalence of RF and inflammatory joint pain. ${ }^{[45]}$ These finding make RF poor diagnostic tool for differentiation between diseases. The isotype distribution is variable among reports. For better differentiation, the use of other biomarkers such as ACPA can be useful, since ACPA is more specific than RF.

RF also can be used as a prognostic factor in RA patients. It is well-known that sero-positive patients have more severe disease: more aggressive form of joint involvement, more extra-articular manifestations. ${ }^{[46,47]}$ In many observations, RFs have been shown to be negatively associated with the achievement of joint remission. IgM, in particular, is a risk factor for not achieving remission. ${ }^{[48]}$ Furthermore, the presence of RF can predict the response to drug therapy, for example, RF and ACPA appear, both associated with better efficacy and lower risk of abatacept discontinuation. ${ }^{[49,50]}$ But for conventional DMARD, that data are not very consistent.

\section{Anti-Citrullinated Peptide Antibody}

\section{Historical Observation}

As mentioned previously, ICs were needed to drive the development of RF. Many antigens were sought in the IC and citrullinated proteins were later found to be a major component of antigens forming the IC. The discovery of ACPA date backs to 1964 when Nienhuis et al. found a perinuclear staining pattern by using scrapping of mucosa cells as target substrates after the incubation with RA serum. ${ }^{[51]}$ Subsequently, Young et al. discovered anti-keratin antibody using rat esophagus section as an alternative substrate and these antibodies turned out to be identical. ${ }^{[52-54]}$ Citrullinated filaggrin was finally elucidated to be the so-called perinuclear factor. ${ }^{[55]}$ This huge step opens the gate for the study of ACPA.

Citrullination is the process in which enzymes called peptidy arginine deiminases (PADs) deiminate arginine-containing proteins. This natural process occurs in many physiological and pathological conditions including inflammation and oncogenesis. ${ }^{[56]}$ Till now, there are five PAD enzyme isoforms and PAD2 and PAD4 are the most strongly implicated in RA. Some distinct characteristics of ACPA are different from that of RF including the isotype distribution, $\mathrm{N}$-glycosylation, somatic hypermutation, B cell activation, and production of plasma cells. ${ }^{[57]}$ The main isotypes for ACPA are $\lg G$ and $\lg A$, which are different from IgM of RF. In contrast to lower level of glycosylation in conventional lgG, more than $90 \%$ of ACPA were found to carry glycans and these glycosylation sites were localized predominantly in the variable domain. It was suggested that the hyperglycosylation in variable domain was introduced by sequence of somatic hypermutation. ${ }^{[58]}$

In the past decades, more than 100 protein candidates for citrullination had been identified. They contain intracellular and extracellular proteins. Collectively, these citrullinated proteins are termed "RA citrullinome." ${ }^{[59,60]}$ Much effort have been focused on demonstrating the presence of specific citrullinated proteins in the synovial tissue. Unfortunately, none of these citrullinated proteins turned out to be a specific antigen and most ACPA were reactive with many antigens, even cross reactive with protein with carbamylation and acetylation. ${ }^{[61,62]}$ Although the targets and magnitude of citrullination may not differ among controls and RA patients in some tissues, it is interesting that the rheumatoid joint is enriched in citrullinated protein. Furthermore, the antigen specificity and avidity can evolve with time. It was demonstrated that repeated somatic hypermutation induced affinity maturation happened in the germinal center to mediate "epitope spreading" and to expand B cell repertoires. ${ }^{[63,64]}$

\section{The Role in Pathophysiology}

Genetic and environmental factors are considered to play major role in the pathogenesis of RA. Compared to normal population, RA patients are identified to carry high prevalence of HLA-DR4 (DRB1*0401 and DRB1*0404), these alleles encode for a specific amino acid sequence known as the shared epitope (SE). ${ }^{[65]}$

Smoking is a major environmental risk factor for the development of RA, which carry very high risk factor up to 2.31. ${ }^{[6]}$ The production of ACPA is highly associated with smoking and SE. The risk of RA development is 20 times higher when the patients are smokers and carry SE. ${ }^{67,68]}$ Smoking is found to activate the PAD and generate ciltrullinated neoantigens. ${ }^{[69]}$ Interestingly, epidemiology study revealed that another mucosa disease, periodontitis caused by pathogens Porphyromonas gingivalis which targets individuals predominately expressing HLA-DRB1*04 alleles highly associated with $\mathrm{RA}^{\left[{ }^{[0,71]} P \text {. gigivalis express }\right.}$ high level of PAD to stimulate the citrullination process and further studies showed that the antibodies produced against this bacterium is highly correlated to the titter of ACPA. ${ }^{[72]}$ Some major source of PADs is intracellular. Through 
different cellular death pathways, the leakage of PADs into surrounding tissue induces the generation of citrullinated protein. The most characteristic cellular death pathways, netosis and autophagy, have shown to induce citrullination of tissue protein such as vimentin and alpha-enolase. ${ }^{[73,74]}$

How the interplays between genetic and environmental factors contribute to the break of tolerance is not well known. However, based on the observation that ACPA had high affinity maturation and strong evidence of occurrence of somatic hypermutation before their secretion, it can be said that CD4 T cell plays an important role. The uptakes of IC by antigen presenting cells with subsequent presentation by HLA molecules that contain SE binding motifs activate specific CD4+ T cells. T cells may in turn provide $B$ cell help to the production of ACPA. Finally, these events lead to the perpetuation of immune response. Evidences have shown that both Toll-like receptor 4 and Fcg receptor mediate the binding of $\mathrm{IC}$ to macrophages followed by the activation of inflammatory cascade. ${ }^{[75]}$ Similar to what RF does, ACPAs are found to activate the complement system, release of $\mathrm{C} 5 \mathrm{a}$ and MAC are observed. Both classical and alternative pathways have their roles in the activation of the complement system. ${ }^{[76]}$

Recently, the pathogenic role of PAD was highlighted by the finding that PAD inhibitors had therapeutic efficacy in mouse models of inflammatory arthritis (IA). In addition, anti-PAD antibodies are used as possible biomarkers for RA diagnosis and prognosis since anti-PAD2 and PAD4 are found in distinct clinical subsets of patients with RA. ${ }^{[56]}$

\section{Clinical Association}

As mentioned previously, ACPAs and RF can both be detected in the pre-RA stage. Base on this finding, several models were set to predict the development of RA. Case control studies indicate that elevated ACPA and/or RF tier have high positive predictive value for RA. ${ }^{[7,}{ }^{78]}$ In a prospective study in Dutch, 347 patients with ACPA and/or RF positivity and arthralgia but no IA at baseline, 35\% developed IA in a median of 12 months. Also, 74\% developed IA/RA within 3 years if

Conflict of Interest

No potential conflicts of interest were disclosed.

\section{References}

[1] Lee DM, Weinblatt ME. Rheumatoid Arthritis. Lancet. 2001;358(9285):903-911.

[2] Wasserman AM. Diagnosis and Management of RA. Am Fam Physician. 2011;84(11):1245-1252. patients have higher composite scores. ${ }^{[79]}$ However, another study revealed that fewer than $50 \%$ of ACPA-positive patients with nonspecific musculoskeletal symptoms develop RA after 1 year. ${ }^{[80]}$ More markers are recruited for the prediction of RA since the presence of ACPAs and/or RF is not sufficient for the prediction of RA development. ${ }^{[81]}$

It is well known that ACPA and/or RF have impact on the disease severity and extra-articular involvement. ACPA and RF seemed to be associated with different extra-articular manifestations. ${ }^{[82,83]}$ Interestingly, CV events are associated with ACPA. Irrespective of inflammation, autoantibodies might affect cardiac function. Epidemiologic study also shows that ACPA is associated with increased CV death. ${ }^{[84]}$ Recently, lung tissue was found to have extensive citrullination on RA patients with interstitial lung disease. ACPA was suggested to play role in the process of lung injury. ${ }^{[85]}$

Finally, ACPA can be used as a marker for drug response. In AMPLE trial, baseline anti-CCP2 positivity was associated with a better response for abatacept and adalimumab. Higher antiCCP2 antibody concentrations had better clinical response with abatacept than patients with lower concentrations. This association was not observed with adalimumab. ${ }^{[86]}$

\section{Conclusion}

RA is a very complex autoimmune disease with variable clinical manifestations. Evidence also identify that several autoantibodies are involved in the pathophysiology of the disease. Two of them, RF and ACPA, are highly prevalent in RA patients. These two autoantibodies provide not only the insights of how immune system is dysregulated but also the clues for clinical diagnosis and managements. Cohort studies reveal that about $60-80 \%$ of RA patients are sero-positive. These patients have specific clinical outcome and treatment response. Nowadays, we can use these biomarkers for better care of our patients. Unfortunately, not every RA patient is seropositive. Further research focused to find more biomarkers will allow us to have a better understanding of the pathogenesis, sub-classification of patients, and algorithm of treatment policy.

[3] Scott DL, Wolfe F, Huizinga TW. Rheumatoid Arthritis. Lancet. 2010;376(9746):1094-1108.

[4] Ibrahim M, Suzuki A, Yamada K, et al. The Relationship Between Cervical and Lumbar Spine Lesions in Rheumatoid 
Arthritis with A Focus on Endplate Erosion. J Spinal Disord Tech. 2015;28(3):E154-E160.

[5] Seki S, Hirano N, Matsushita I, et al. Lumbar Spine Surgery in Patients with Rheumatoid Arthritis (RA): What Affects the Outcomes? Spine J. 2018;18(1):99-106.

[6] Spagnolo P, Lee JS, Sverzellati N, et al. The Lung in Rheumatoid Arthritis: Focus on Interstitial Lung Diseases. Arthritis Rheumatol. 2018;70(10):1544-1554.

[7] Johnson C. Recent Advances in the Pathogenesis, Prediction, and Management of Rheumatoid Arthritis-Associated Interstitial Lung Disease. Curr Opin Rheumatol 2017;29(3):254-259.

[8] Tong L, Thumboo J, Tan YK, et al. The Eye: A Window of Opportunity in Rheumatoid Arthritis? Nat Rev Rheumatol. 2014;10(9):552-560.

[9] Anyfanti P, Triantafyllou A, Gkaliagkousi E, et al. Retinal Vesse Morphology in Rheumatoid Arthritis: Association with Systemic Inflammation, Subclinical Atherosclerosis, and Cardiovascular Risk. Microcirculation. 2017;24(8):e12417.

[10] England BR, Thiele GM, Anderson DR, et al. Increased Cardiovascular Risk in Rheumatoid Arthritis: Mechanisms and Implications. BMJ. 2018;361:k1036.

[11] Bugatti S, Manzo A, Montecucco C, et al. The Clinical Value of Autoantibodies in Rheumatoid Arthritis. Front Med (Lausanne). 2018;5:339.

[12] Conigliaro $P$, Chimenti MS, Triggianese $P$, et al. Autoantibodies in Inflammatory Arthritis. Autoimmun Rev. 2016;15(7):673683.

[13] van Delft MAM, Huizinga TWJ. An Overview of Autoantibodies in Rheumatoid Arthritis. J Autoimmun. 2020;110:102392.

[14] Song YW, Kang EH. Autoantibodies in Rheumatoid Arthritis. QJM. 2010;103(3):139-146.

[15] Mclnnes IB, Schett G. The Pathogenesis of Rheumatoid Arthritis. N Engl J Med. 2011;365:2205-2219.

[16] Lucchino B, Spinelli FR, lannuccelli C, et al. MucosaEnvironment Interactions in the Pathogenesis of Rheumatoid Arthritis. Cells. 2019;8:700-721.

[17] Smolen JS, Aletaha D, Mclnnes IB. Rheumatoid Arthritis. Lancet. 2017;388:2023-2038.

[18] Gerlag DM, Raza K, van Baarsen LGM, et al. EULAR Recommendations for Terminology and Research in Individuals at Risk of Rheumatoid Arthritis: Report from the Study Group for Risk Factors for Rheumatoid Arthritis. Ann Rheum Dis. 2012;71:638-641.

[19] Nielen MM, van Schaardenburg D, Reesink HW, et al. Specific Autoantibodies Precede the Symptoms of Rheumatoid Arthritis: A Study of Serial Measurements in Blood Donors. Arthritis Rheum. 2004;50(2):380-386.

[20] Deane KD, Norris JM, Holers VM. Preclinical Rheumatoid Arthritis: Identification, Evaluation, and Future Directions for Investigation. Rheum Dis Clin. 2010;36:213-241.

[21] Waaler E. On the Occurrence of A Factor in Human Serum
Activating the Specific Agglutination of Sheep Blood Corpuscles, Acta Pathol Microbiol Scand. 1940;17(2):172188.

[22] Plike RM, Sulkin SE, Coggeshall HC. Serological Reactions in Rheumatoid Arthritis; Factors Affecting the Agglutination of Sensitized Sheep Erythrocytes in Rheumatid-Arthritis Serum. J Immunol. 1949;63(4):441-446.

[23] Plike RM, Sulkin SE, Coggeshall HC. Serological Reactions in Rheumatoid Arthritis. III. Increased Agglutination of Sensitized Sheep Erythrocytes in the Presence of Normal Animal Sera. J Immunol. 1951;66(1):107-113.

[24] Franklin EC, Holman HR, Muller-Eberhard HJ, et al. An Unusual Protein Component of High Molecular Weight in the Serum of Certain Patients with Rheumatoid Arthritis. J Exp Med. 1957;105:425-438.

[25] Edelman GM, Kunkel HG, Franklin EC. Interaction of the Rheumatoid Factor with Antigen-Antibody Complexes and Aggregated Gamma Globulin. J Exp Med. 1958;108:105-120.

[26] Abruzzo JL, Christian CL. The Induction of A Rheumatoid Factor-Like Substance in Rabbits. J Exp Med. 1961;114:791806.

[27] Williams RC Jr., Kunkel HG. Rheumatoid Factor, Complement, and Conglutinin Aberrations in Patients with Subacute Bacterial Endocarditis. J Clin Invest. 1962;41:666-675.

[28] Simard JF, Holmqvist M. Rheumatoid Factor Positivity in the General Population. Br Med J. 2012;345:e5841.

[29] Newkirk MM. Rheumatoid Factors: What Do They Tell Us? J Rheumatol. 2002;29(10):2034-2040.

[30] Winchester RJ, Agnello V, Kunkel HG. Gamma Globulin Complexes in Synovial Fluids of Patients with Rheumatoid Arthritis. Partial Characterization and Relationship to Lowered Complement Levels. Clin Exp Immunol. 1970;6:689-706.

[31] Moxley G, Ruddy S. Elevated C3 Anaphylatoxin Levels in Synovial Fluids from Patients with Rheumatoid Arthritis. Arthritis Rheum. 1985;28:1089-1095.

[32] Jose PJ, Moss IK, Maini RN, et al. Measurement of the Chemotactic Complement Fragment $\mathrm{C5a}$ in Rheumatoid Synovial Fluids by Radioimmunoassay: Role of C5a in the Acute Inflammatory Phase. Ann Rheum Dis. 1990;49:747752.

[33] Yamamoto T, Nishiura H, Nishida H. Molecular Mechanisms to Form Leukocyte Infiltration Patterns Distinct Between Synovial Tissue and Fluid of Rheumatoid Arthritis. Semin Thromb Hemost. 1996;22:507-511.

[34] Newkirk MM. Rheumatoid Factors: Host Resistance or Autoimmunity? Clin Immunol. 2002;104(1):1-13.

[35] Shmerling RH, Delbanco TL. The Rheumatoid Factor: An Analysis of Clinical Utility. Am J Med. 1991;91(5):528-534.

[36] Børretzen M, Chapman C, Natvig JB, et al. Differences in Mutational Patterns Between Rheumatoid Factors in Health and Disease are Related to Variable Heavy Chain Family and Germ-Line Gene Usage. Eur J Immunol. 1997;27(3):735-741. 
[37] Slaughter L, Carson DA, Jensen FC. In Vitro Effects of Epstein-Barr Virus on Peripheral Blood Mononuclear Cells from Patients with Rheumatoid Arthritis and Normal Subjects. J Exp Med. 1978;148(5):1429-1434.

[38] Dresser DW. Most IgM-Producing Cells in the Mouse Secrete Auto-Antibodies (Rheumatoid Factor). Nature. 1978;274(5670):480-483.

[39] Nell VP, Machold KP, Stamm TA, et al. Autoantibody Profiling as Early Diagnostic and Prognostic Tool for Rheumatoid Arthritis. Ann Rheum Dis. 2005;64:1731-1736.

[40] Nielsen SF, Bojesen SE, Schnohr P, et al. Elevated Rheumatoid Factor and Long Term Risk of Rheumatoid Arthritis: A Prospective Cohort Study. BMJ. 2012;345:e5244.

[41] Deane KD, O'Donnell Cl, Hueber W, et al. The Number of Elevated Cytokines and Chemokines in Preclinical Seropositive Rheumatoid Arthritis Predicts Time to Diagnosis in an Agedependent Manner. Arthritis Rheum. 2010;62(11):3161-3172.

[42] Miller A, Mahtani KR, Waterfield MA, et al. Is Rheumatoid Factor Useful in Primary Care? A Retrospective CrossSectional Study. Clin Rheumatol. 2013;32(7):1089-1093.

[43] Lienesch D, Morris R, Metzger A, et al. Absence of Cyclic Citrullinated Peptide Antibody in Nonarthritic Patients with Chronic Hepatitis C Infection. J Rheumatol. 2005;32(3):489493.

[44] Lee SI, Yoo WH, Yun HJ, et al. Absence of Antibody to Cyclic Citrullinated Peptide in Sera of Non-Arthritic Patients with Chronic Hepatitis B Virus Infection. Clin Rheumatol. 2007;26(7):1079-1082.

[45] Vallbracht I, Rieber J, Oppermann M, et al. Diagnostic and Clinical Value of Anti-Cyclic Citrullinated Peptide Antibodies Compared with Rheumatoid Factor Isotypes in Rheumatoid Arthritis. Ann Rheum Dis. 2004;63(9):1079-1084.

[46] Jónsson T, Arinbjarnarson S, Thorsteinsson J, et al. Raised IgA Rheumatoid Factor (RF) but not IgM RF or IgG RF is Associated with Extraarticular Manifestations in Rheumatoid Arthritis. Scand J Rheumatol. 1995;24:372-375.

[47] Paimela L, Palosuo T, Leirisalo-Repo M, et al. Prognostic Value of Quantitative Measurement of Rheumatoid Factor in Early Rheumatoid Arthritis. Br J Rheumatol. 1995;34(12):1146-1150.

[48] Verstappen SM, van Albada-Kuipers GA, Bijlsma JW, et al. A Good Response to Early DMARD Treatment of Patients with Rheumatoid Arthritis in the First Year Predicts Remission During Follow Up. Ann Rheum Dis. 2005;64:38-43.

[49] Nüßlein HG, Alten R, Galeazzi M, et al. Efficacy and Prognostic Factors of Treatment Retention with Intravenous Abatacept for Rheumatoid Arthritis: 24-Month Results from An International, Prospective, Real-World Study. Clin Exp Rheumatol. 2016;34:489-499.

[50] Alten R, Nüßlein HG, Mariette X, et al. Baseline Autoantibodies Preferentially Impact Abatacept Efficacy in Patients with Rheumatoid Arthritis who are Biologic Naïve: 6-Month Results from a Real-World, International, Prospective Study. RMD
Open. 2017;3:e000345

[51] Nienhuis RL, Mandema E. A New Serum Factor in Patients with Rheumatoid Arthritis; the Antiperinuclear Factor. Ann Rheum Dis. 1964;23:302-305.

[52] Young BJ, Mallya RK, Leslie RD, et al. Anti-Keratin Antibodies in Rheumatoid Arthritis. BMJ. 1979;2:97-99.

[53] Catalano MA, Carson DA, Niederman JC, et al. Antibody to the Rheumatoid Arthritis Nuclear Antigen. Its Relationship to In Vivo Epstein-Barr Virus Infection. J Clin Invest. 1980;65:12381242.

[54] Ferrell PB, Aitcheson CT, Pearson GR, et al. Seroepidemiological Study of Relationships Between Epstein-Barr Virus and Rheumatoid Arthritis. J Clin Invest. 1981;67:681-687.

[55] Schellekens GA, de Jong BA, van den Hoogen $\mathrm{FH}$, et al. Citrulline is an Essential Constituent of Antigenic Determinants Recognized by Rheumatoid Arthritis-Specific Autoantibodies. J Clin Invest. 1998;101:273-281.

[56] Curran AM, Naik P, Giles JT, et al. PAD Enzymes in Rheumatoid Arthritis: Pathogenic Effectors and Autoimmune Targets. Nat Rev Rheumatol. 2020;16(6):301-315.

[57] Wu CY, Yang HY Lai JH. Anti-Citrullinated Protein Antibodies in Patients with Rheumatoid Arthritis: Biological Effects and Mechanisms of Immunopathogenesis. Int J Mol Sci. 2020;21:4015.

[58] Vergroesen RD, Slot LM, Hafkenscheid L, et al. B-Cell Receptor Sequencing of Anti-Citrullinated Protein Antibody (ACPA) IgG-Expressing B Cells Indicates A Selective Advantage for the Introduction of N-Glycosylation Sites During Somatic Hypermutation. Ann Rheum Dis. 2018;77: 956-958.

[59] Van Beers JJ, Schwarte CM, Stammen-Vogelzangs J, et al. The Rheumatoid Arthritis Synovial Fluid Citrullinome Reveals Novel Citrullinated Epitopes in Apolipoprotein E, Myeloid Nuclear Differentiation Antigen, and Beta-Actin. Arthritis Rheum. 2013;65:69-80.

[60] Tilvawala R, Nguyen SH, Maurais AJ, et al. The Rheumatoid Arthritis-Associated Citrullinome. Cell Chem Biol. 2018;25:691-770.

[61] Kampstra ASB, Dekkers JS, Volkov M, et al. Different Classes of Anti-Modified Protein Antibodies are Induced on Exposure to Antigens Expressing Only One Type of Modification. Ann Rheum Dis. 2019;78:908-916.

[62] Shi J, Willemze A, Janssen GM, et al. Recognition of Citrullinated and Carbamylated Proteins by Human Antibodies: Specificity, Cross-Reactivity and the 'AMC-Senshu' Method. Ann Rheum Dis. 2013;72:148-150.

[63] Van der Woude D, Rantapaa-Dahlqvist S, loan-Facsinay A, et al. Epitope Spreading of the Anti-Citrullinated Protein Antibody Response Occurs Before Disease Onset and is Associated with the Disease Course of Early Arthritis. Ann Rheum Dis. 2010;69:1554-1561. 
[64] Kongpachith S, Lingampalli N, Ju CH, et al. Affinity Maturation of the Anti-Citrullinated Protein Antibody Paratope Drives Epitope Spreading and Polyreactivity in Rheumatoid Arthritis. Arthritis Rheumatol. 2019;71:507-517.

[65] Gregersen PK, Silver J, Winchester RJ. The Shared Epitope Hypothesis. An Approach to Understanding the Molecular Genetics of Susceptibility to Rheumatoid Arthritis. Arthritis Rheumatol. 1987;30(11):1205-1213.

[66] Di Giuseppe D, Orsini N, Alfredsson L, et al. Cigarette Smoking and Smoking Cessation in Relation to Risk of Rheumatoid Arthritis in Women. Arthritis Res Ther. 2013;15(2):R56.

[67] Kallberg H, Ding B, Padyukov L, et al. Smoking is a Major Preventable Risk Factor for Rheumatoid Arthritis: Estimations of Risks after Various Exposures to Cigarette Smoke. Ann Rheum Dis. 2011;70:508-511.

[68] Sparks JA, Chang SC, Deane KD, et al. Associations of Smoking and Age with Inflammatory Joint Signs Among Unaffected First-Degree Relatives of Rheumatoid Arthritis Patients: Results from Studies of the Etiology of Rheumatoid Arthritis. Arthritis Rhematol. 2016;68:1828-1838.

[69] Makrygiannakis D, Hermansson M, Ulfgren A-K, et al. Smoking Increases Peptidylarginine Deiminase 2 Enzyme Expression in Human Lungs and Increases Citrullination in BAL Cells. Ann Rheum Dis. 2008;67:1488-1492.

[70] Baka Z, György B, Géher P, et al. Citrullination Under Physiological and Pathological Conditions. Joint Bone Spine. 2012;79:431-436.

[71] Berthelot JM, Le Goff B. Rheumatoid Arthritis and Periodontal Disease. Joint Bone Spine. 2010;77:537-541.

[72] Mikuls TR, Payne JB, Reinhardt RA, et al. Antibody Responses to Porphyromonas Gingivalis ( $P$. gingivalis) in Subjects with Rheumatoid Arthritis and Periodontitis. Int Immunopharmacol. 2009;9:38-42.

[75] Sokolove J, Zhao X, Chandra PE, et al. Immune Complexes Containing Citrullinated Fibrinogen Costimulate Macrophages via Toll-Like Receptor 4 and Fcgamma Receptor. Arthritis Rheum. 2011;63:53-62.

[76] Trouw LA, Haisma EM, Levarht EW, et al. Anti-Cyclic Citrullinated Peptide Antibodies from Rheumatoid Arthritis Patients Activate Complement via Both the Classical and Alternative Pathways. Arthritis Rheum. 2009;60:1923-1931.
[77]. Rantapää-Dahlqvist S, de Jong BAW, Berglin E, et al. Antibodies Against Cyclic Citrullinated Peptide and IgA Rheumatoid Factor Predict the Development of Rheumatoid Arthritis. Arthritis Rheum. 2003;48(10):2741-2749.

[78] Nielen MMJ, van Schaardenburg D, Reesink HW, et al. Specific Autoantibodies Precede the Symptoms of Rheumatoid Arthritis: A Study of Serial Measurements in Blood Donors. Arthritis Rheum. 2004;50(2):380-386.

[79] van de Stadt LA, Witte BI, Bos WH, et al. A Prediction Rule for the Development of Arthritis in Seropositive Arthralgia Patients. Ann Rheum Dis. 2013;72:1920-1926.

[80] Rakieh C, Nam JL, Hunt L, et al. Predicting the Development of Clinical Arthritis in Anti-CCP Positive Individuals with Non-Specific Musculoskeletal Symptoms: A Prospective Observational Cohort Study. Ann Rheum Dis. 2015;74:16591666.

[81] Triple Positivity for Anti-Citrullinated Protein Autoantibodies, Rheumatoid Factor, and Anti-Carbamylated Protein Antibodies Conferring High Specificity for Rheumatoid Arthritis. Arthritis Rheum. 2018;70:1721-1731.

[82] De Rycke L, Peene I, Hoffman IE, et al. Rheumatoid Factor and Anticitrullinated Protein Antibodies in Rheumatoid Arthritis: Diagnostic Value, Associations with Radiological Progression Rate, and Extra-articular Manifestations. Ann Rheum Dis. 2004;63:1587-1593.

[83] Bongartz T, Cantaert T, Atkins SR, et al. Citrullination in Extra-Articular Manifestations of Rheumatoid Arthritis. Rheumatology. 2007;46:70-75.

[84] Ajeganova S, Humphreys JH, Verheul MK, et al. Anticitrullinated Protein Antibodies and Rheumatoid Factor are Associated with Increased Mortality but with Different Causes of Death in Patients with Rheumatoid Arthritis: A Longitudinal Study in Three European Cohorts. Ann Rheum Dis. 2016;75:1924-1932.

[85] Spagnolo $P$, Lee JS, Sverzellati $N$, et al. The Lung in Rheumatoid Arthritis. Focus on Interstitial Lung Disease. Arthritis Rheum. 2018;70:1544-1554.

[86] Sokolove J, Schiff M, Fleischmann R, et al. Impact of Baseline Anti-Cyclic Citrullinated Peptide-2 Antibody Concentration on Efficacy Outcomes Following Treatment with Subcutaneous Abatacept or Adalimumab: 2-Year Results from the AMPLE Trial. Ann Rheum Dis. 2016;75:709-714. 